\title{
Evolutionary cytogenetics of the Drosophila buzzatii species complex
}

\author{
ALFREDO RUIZ* \& MARVIN WASSERMAN $\dagger$ \\ *Departament de Genètica i de Microbiologia, Universitat Autònoma de Barcelona, 08193 Bellaterra (Barcelona), Spain; \\ and †Department of Biology, Queens College of the City University of New York, Flushing, New York 11367-0904, \\ U.S.A.
}

\begin{abstract}
The salivary gland chromosomes of 10 species in the Drosophila mulleri subgroup (repleta group) have been re-analysed. These include the eight members of the South American buzzatii and martensis clusters, previously ascribed to the mulleri complex, and the two Caribbean species $D$. stalkeri and $D$. richardsoni, previously comprising the stalkeri complex. The chief results can be summarized as follows. Inversion 3a is not present in the martensis cluster. Hence, there is no cytological link between this cluster, or the buzzatii cluster, and the rest of the mulleri complex. Accordingly, a new species complex, the buzzatii complex, is established with the two South American clusters. D. stalkeri and D. richardsoni share at least two inversions with all the species in the buzzatii and martensis clusters, and produce hybrids in interspecific crosses with many of them. This indicates a close phylogenetic relationship. Therefore, D. stalkeri and D. richardsoni are incorporated as a cluster within the newly erected buzzatii complex. A phylogenetic tree illustrating the chromosomal evolution of the buzzatii complex is presented and all the previous cytological information concerning its members is reviewed.
\end{abstract}

Keywords: chromosomal evolution, Drosophila repleta species group, paracentric inversions, phylogeny.

\section{Introduction}

Changes in the number and shapes of chromosomes, resulting from reciprocal translocations, centric fissions and fusions, inversions, and additions and deletions of heterochromatin, have been used to determine phylogenetic relationships for many years (White, 1948). The rediscovery of the giant salivary chromosome with its somatic pairing of homologs in many of the species of the Diptera has resulted in an increase in the resolving power of at least two orders of magnitude above even the most modern banding techniques used in the study of mitotic chromosomes (Clayton \& Guest, 1986).

Sturtevant \& Dobzhansky (1936) showed that overlapping paracentric inversions can show phylogenetic relationships, but not the direction of evolution. Wasserman $(1963,1992)$ stated that each inversion is probably not a unique event but can occur more than once in more than one population. However, he argued

Correspondence: Dr Alfredo Ruiz, Departament de Genètica i de Microbiologia, Edifici C, Universitat Autònoma de Barcelona, 08193 Bellaterra (Barcelona), Spain. that the probability of the occurrence and survival of the same inversion in two independent evolutionary lines is so minute that one can assume that each inversion is unique and that any two species which have the same inversion are more closely related to each other than either is to a third species which lacks the inversion. Wasserman $(1963,1992)$ also discussed the types of errors that could be made in this type of work. These included observational mistakes, and errors due to parallel and convergent evolution. Observational errors are relatively uncommon, but unfortunately may be important. They are, however, potentially correctable by further work, especially if and when hybrids can be produced between the species in question. Moreover, the discovery of intermediate forms, if present, can at least indicate whether parallel or convergent evolution has taken place.

One of the 'rules' basic to this type of work is that where there is more than one possible evolutionary pathway to go from one taxon to another, the shortest, most parsimonious route is chosen. A confounding problem may also exist where there is a sharing of inversions among species such that the distribution of 
the inversions among the species cannot be explained by the usual allopatric paradigms. In the Drosophila repleta species group, sharing of inversions has been proposed as occurring in the $D$. repleta subgroup and in the D. mulleri subgroup (Wasserman 1982, 1992).

The Drosophila mulleri species complex of the mulleri subgroup was defined by Wasserman (1982) as consisting of 23 cactus-inhabiting species which share and are homozygous for one or more of the following 11 inversions: $\mathrm{Xj}, \mathrm{Xw}, 2 \mathrm{c}, 2 \mathrm{f}, 2 \mathrm{~g}, 2 \mathrm{~h}, 2 \mathrm{~d}^{2}, 2 \mathrm{e}^{2}, 2 \mathrm{~s}^{6}$, $3 \mathrm{a}$ and 3c. According to Wasserman (1954, 1962, 1982), the ancestor of the mulleri complex consisted of a number of semi-isolated cytologically distinct populations which for convenience were referred to as subspecies. Each subspecies gave rise, apparently by means of the usual speciation by geographical isolation, to several extant species. The progeny species of each ancestral subspecies were grouped into six species clusters (Wasserman, 1982). The mojavensis, longicornis and ritae clusters are essentially North American in distribution; the buzzatii and martensis clusters are primarily South American; while the mulleri cluster is represented throughout the New World.

All of the species of the South American clusters are limited to the New World except for D. buzzatii which is now subcosmopolitan (Fontdevila et al., 1981; Barker, 1982). The martensis cluster, with four species, is found in the deserts of Colombia and Venezuela, and the nearby islands of the Caribbean (Wasserman \& Koepfer, 1979; Ruiz \& Fontdevila, 1981); while the buzzatii cluster, also with four species, ranges from north eastern Brazil to north western Argentina and Bolivia (Sene et al., 1982, 1988; Ruiz et al., 1982; Wasserman \& Richardson, 1987; Fontdevila et al., 1988).

The South American martensis and buzzatii clusters share three inversions on chromosome 2 which are absent in the other four clusters (Ruiz et al., 1982) and are, thus, phylogenetically quite closely related. The only cytological link between the two South American clusters and the other clusters in the mulleri complex is the $3 \mathrm{a}$ inversion which was believed to be present in all the species of the four North American clusters except the species $D$. arizonae, and in all the species of the South American martensis cluster but not in those of the buzzatii cluster (Wasserman, 1982).

We report here the results of a complete re-analysis of the salivary gland chromosomes of the eight species in the martensis and buzzatii clusters. This re-analysis was fostered by the following observations.

1 Two collecting trips to the West Indies have made available a number of new populations of the two closely related species $D$. stalkeri and $D$. richardsoni, which belong to the mulleri subgroup but which were placed in a different species complex, the stalkeri complex (Wasserman, 1982). While investigating their salivary gland chromosomes, a striking resemblance was observed by Ruiz between chromosome 2 of $D$. stalkeri and that of $D$. buzzatii uncovering an unexpected possible phylogenetic relationship between the stalkeri complex, on the one hand, and the buzzatii cluster on the other.

2 Ruiz recently was able to show that 3a was in fact present in D. arizonae (Ruiz et al., 1990). This encouraged the re-examination of chromosome 3 in the martensis cluster to determine whether the inversion there was indeed $3 \mathrm{a}$.

3 Of considerable importance was the discovery that $D$. stalkeri and $D$. richardsoni hybridize rather easily with some of the species in the martensis, buzzatii and mulleri clusters (Marin et al., in press). We have made use of this fact to produce hybrids of 11 different interspecific combinations and analyse their salivary gland chromosomes.

Here, we are presenting evidence which demonstrates that: (i) the $3 a$ inversion is not present in the martensis cluster. Thus the only remaining link between the two South American clusters and the rest of the mulleri complex is broken. The mulleri complex is therefore reduced to the mojavensis, mulleri, longicornis and ritae clusters, while a new complex, the buzzatii complex, is established for the South American clusters; (ii) the production of previously unstudied interspecific hybrids demonstrates that the two species of the stalkeri complex are related to the buzzatii and martensis clusters and are, therefore, members of the buzzatii complex; (iii) the incorporation of the stalkeri complex, as a cluster, into the buzzatii complex results in convergent evolution where there are two, nearly equal-length, evolutionary paths from the PRIMITIVE I sequence to the most advanced gene orders; the stalkeri cluster is cytologically either the most primitive or the most advanced cluster of the buzzatii complex. The simplest phylogenetic tree has the stalkeri cluster as the primitive cluster of the complex. This not only results in the 'most parsimonious' phylogenetic tree but also eliminates several examples of alleged sharing of inversions.

\section{Materials and methods}

Four stocks of Drosophila stalkeri and eight stocks of D. richardsoni were cytologically analysed (Table 1). The collection localities cover the entire known geographical range of these two species (see Marin et al., in press, for the geographical position of localities). One strain of D. stalkeri from Saint Petersburg (Wasserman, 1962) and one strain of D. richardsoni 
Table 1 Chromosomal constitution of the 12 stocks of D. stalkeri and $D$. richardsoni investigated in this study. Numbers of stocks used in the interspecific crosses are shown in boldface

\begin{tabular}{|c|c|c|c|c|c|c|c|}
\hline \multirow{2}{*}{$\begin{array}{l}\text { Drosophila } \\
\text { species }\end{array}$} & \multirow{2}{*}{$\begin{array}{l}\text { Stock } \\
\text { number }\end{array}$} & \multirow[b]{2}{*}{ Locality } & \multicolumn{5}{|c|}{ Chromosome arrangements } \\
\hline & & & Xabc & $2 \mathrm{mn}$ & $3 b$ & 4 & 5 \\
\hline \multirow[t]{4}{*}{ stalkeri } & $\begin{array}{l}15801- \\
1451.0\end{array}$ & $\begin{array}{l}\text { St. Petersburg, } \\
\text { Florida }\end{array}$ & + & 1 & + & + & + \\
\hline & ORV 25 & $\begin{array}{l}\text { Discovery Bay, } \\
\text { Jamaica }\end{array}$ & + & 1 & + & + & + \\
\hline & ORV 28 & $\begin{array}{l}\text { Little Cayman, } \\
\text { Cayman Islands }\end{array}$ & + & 1 & + & + & + \\
\hline & ORV 29 & $\begin{array}{l}\text { Grand Cayman, } \\
\text { Cayman Islands }\end{array}$ & + & 1 & + & + & + \\
\hline \multirow[t]{8}{*}{ richardsoni } & ORV 6 & $\begin{array}{l}\text { Fox's Bay, } \\
\text { Montserrat }\end{array}$ & + & $w^{7} y^{7}$ & + & + & + \\
\hline & ORV 7a & $\begin{array}{l}\text { Montserrat } \\
\text { Airport }\end{array}$ & + & $w^{7} y^{7}$ & + & + & + \\
\hline & ORV $7 b$ & $\begin{array}{l}\text { Montserrat } \\
\text { Airport }\end{array}$ & + & $w^{7} y^{7}$ & + & + & + \\
\hline & ORV $7 \mathrm{c}$ & $\begin{array}{l}\text { Spanish Point, } \\
\text { Montserrat }\end{array}$ & + & $w^{7} y^{7}$ & + & + & + \\
\hline & ORV $8 \mathrm{a}$ & $\begin{array}{l}\text { Beef Island, } \\
\text { Tortola }\end{array}$ & + & $w^{7} y^{7} p^{8}$ & + & + & + \\
\hline & OVR 8b & $\begin{array}{l}\text { Beef Island, } \\
\text { Tortola }\end{array}$ & + & $\begin{array}{l}w^{7} y^{7} p^{8} \\
w^{7} y^{7} q^{9}\end{array}$ & + & + & + \\
\hline & ORV 9a & $\begin{array}{l}\text { Biras Creek, } \\
\text { Virgin Gorda }\end{array}$ & + & $w^{7} y^{7} p^{8}$ & + & + & + \\
\hline & ORV 9b & $\begin{array}{l}\text { Biras Creek, } \\
\text { Virgin Gorda }\end{array}$ & + & $w^{7} y^{7} p^{8}$ & + & + & + \\
\hline
\end{tabular}

called 'from Puerto Rico' (Wasserman, 1982) had been previously studied. The remaining 11 stocks were derived from new material collected in the West Indies by William B. Heed and Marvin Wasserman 3-27 May 1982 (D. richardsoni) and 16 November-1 December, 1983 (D. stalkeri).

In addition, the salivary gland chromosomes of 13 stocks of the eight described species which make up the buzzatii and martensis clusters (Table 2) and a strain of $D$. mulleri from Great Inagua were analysed in order to check the inversions fixed in each of the species and to compare them with those fixed in D. stalkeri and D. richardsoni. These stocks came from the National Drosophila Species Resource Center at Bowling Green or from the stock collection of the Department de Genètica i de Microbiologia, Universitat Autònoma de Barcelona, and have been kept in culture for a number of years.

The monomorphic gene orders of the species $D$. repleta, symbolized as $\mathrm{XR}, 2 \mathrm{R}, 3 \mathrm{R}, 4 \mathrm{R}, 5 \mathrm{R}, 6 \mathrm{R}$, had initially been chosen as the standard for the cytotaxonomic study of the repleta group (Wasserman, 1954).
The salivary gland chromosomes of each species were compared with these sequences and all changes in the gene orders were assumed to be due to 2-break simple paracentric inversions. Each inversion was named in the order in which it was found, the number indicating the chromosome (X,2,3,4, or 5) and the letter specifying the particular inversion ( $\mathrm{Xa}, 3 \mathrm{~b}, 2 \mathrm{~g}^{3}$, etc.). Each species was then given a cytological formula listing the inversions by which it differed from the species, $D$. repleta. The investigation soon led to the conclusion that the most probable ancestral sequence was not the repleta standard but one differing from it by at least six inversions, $\mathrm{Xa}, \mathrm{Xb}, \mathrm{Xc}, 2 \mathrm{a}, 2 \mathrm{~b}$, and $3 \mathrm{~b}$. The sequence $\mathrm{Xabc} ; 2 \mathrm{ab} ; 3 \mathrm{~b} ; 4 \mathrm{R} ; 5 \mathrm{R}$ was designated as PRIMITIVE I (Wasserman, 1960, 1982).

Parenthetically, while investigating the salivary gland chromosomes of the buzzatii complex species, a discrepancy was noted in the proximal region of chromosome 2 (section F6a-H in the map drawn by Wharton, 1942) which should have identical banding pattern in $D$. repleta and many other species, e.g. $D$. hydei. This discrepancy had been already noted by Berendes 
Table 2 Chromosomal constitution of the 13 stocks of the buzzatii and martensis clusters analysed in this study. Numbers of the stocks used in the interspecific crosses are shown in boldface

\begin{tabular}{|c|c|c|c|c|c|c|c|}
\hline \multirow{2}{*}{$\begin{array}{l}\text { Drosophila } \\
\text { species }\end{array}$} & \multirow{2}{*}{$\begin{array}{l}\text { Stock } \\
\text { number }\end{array}$} & \multirow[b]{2}{*}{ Locality } & \multicolumn{5}{|c|}{ Chromosome arrangements } \\
\hline & & & Xabc & $2 \mathrm{abmnz} \mathrm{z}^{7}$ & $3 b$ & 4 & 5 \\
\hline \multirow[t]{2}{*}{ buzzatii* } & $\mathrm{BU}-\mathrm{C} 5$ & $\begin{array}{l}\text { Adeje, Canary } \\
\text { Islands }\end{array}$ & + & + & + & + & $\mathrm{g}$ \\
\hline & BU-2ST & $\begin{array}{l}\text { Carboneras, } \\
\text { Spain }\end{array}$ & + & + & + & + & $\mathrm{g}$ \\
\hline serido & $\begin{array}{l}15081- \\
1431.4\end{array}$ & $\begin{array}{l}\text { Cafarnaum, } \\
\text { Brazil }\end{array}$ & + & $x^{7} a^{8}$ & + & + & + \\
\hline borborema & $\begin{array}{l}15081- \\
1281.0\end{array}$ & $\begin{array}{l}\text { Cafarnaum, } \\
\text { Brazil }\end{array}$ & + & $e^{8} f^{8}$ & + & + & + \\
\hline \multirow[t]{3}{*}{ koepferae } & $\mathrm{KO}-4$ & $\begin{array}{l}\text { Vipos, } \\
\text { Argentina }\end{array}$ & + & $\begin{array}{l}j^{9} k^{9} \\
j^{9} l^{9} m^{9} n^{9}\end{array}$ & $\mathrm{k}^{2}$ & $\mathrm{~m}$ & w \\
\hline & KO-9 & $\begin{array}{l}\text { San Isidro, } \\
\text { Bolivia }\end{array}$ & + & $j^{9} k^{9}$ & + & + & + \\
\hline & KO-11 & $\begin{array}{l}\text { San Isidro, } \\
\text { Bolivia }\end{array}$ & + & $\begin{array}{l}j^{9} \\
j^{9} k^{9}\end{array}$ & + & + & + \\
\hline martensis & MA-4 & $\begin{array}{l}\text { Guaca, } \\
\text { Venezuela }\end{array}$ & j & $\mathrm{f}^{2}$ & $r^{2} w k$ & + & $d^{2}$ \\
\hline starmeri & SM-3 & $\begin{array}{l}\text { Mal Pais, } \\
\text { Curaçao }\end{array}$ & $\begin{array}{l}\mathrm{j} \\
\mathrm{jq}\end{array}$ & $\begin{array}{l}e^{2} e^{7} \\
e^{2} f^{2} x^{6} z^{6}\end{array}$ & $r^{2} w v$ & + & $d^{2}$ \\
\hline \multirow[t]{2}{*}{ venezolana } & $V Z-2$ & $\begin{array}{l}\text { Piritu, } \\
\text { Venezuela }\end{array}$ & $\mathrm{j}$ & $e^{2} e^{7}$ & $r^{2} w v$ & + & $d^{2}$ \\
\hline & VZ-10 & $\begin{array}{l}\text { La Blanquilla, } \\
\text { Venezuela }\end{array}$ & $\mathrm{j}$ & $e^{2} e^{7}$ & $r^{2} w v$ & + & $d^{2}$ \\
\hline \multirow[t]{2}{*}{ uniseta } & UN-2 & $\begin{array}{l}\text { Guaca, } \\
\text { Venezuela }\end{array}$ & $\mathrm{jr}$ & $e^{2} t^{6} u^{6}$ & $r^{2} w v$ & + & $d^{2}$ \\
\hline & UN-5 & $\begin{array}{l}\text { La Boca, } \\
\text { Venezuela }\end{array}$ & $\mathrm{jr}$ & $e^{2} t^{6} u^{6}$ & $r^{2} w v$ & + & $d^{2}$ \\
\hline
\end{tabular}

*Both stocks were made homokaryotypic for arrangements 2 st and 4 st in the laboratory.

(1963) who was unable to homologize this region between $D$. repleta and $D$. hydei. Therefore, a detailed (band-by-band) comparison of this region was carried out in several species by A.R. The results of this comparison may be summarized as follows: (i) $D$. neorepleta (stock A30.7 from Madera Canyon, Arizona), a sibling species of $D$. repleta, has in this chromosome region the same sequence as $D$. repleta; (ii) $D$. peninsularis (stock 951.8 from Barahona, Dominican Republic) has a sequence which seems to differ from that of $D$. repleta by a short inversion, $2 \mathrm{u}^{8}$, with breakpoints F6c-G1h; (iii) all other species examined have a sequence which seems to differ from that of $D$. peninsularis by a short inversion, $2 t^{8}$, with break-points G1f-G2f, which partially overlaps $2 \mathrm{u}^{8}$. These include D. hydei (stock 813.38 from El Salvador), a member of the hydei subgroup, and D. mulleri (stock from Lake Travis), D. meridiana rioensis (stock 403.8 from Huaju- apan de Leon, Oaxaca), D. arizonae (stock A893 from Navojoa, Sonora), D. navojoa (stock A878 from Eldorado, Sinoloa), D. martensis (stock from Guaca, Venezuela), and D. starmeri (stock from Barquisimeto, Venezuela), all members of the mulleri subgroup. The obvious conclusion is that the PRIMITIVE I sequence contains at least two more inversions, $2 t^{8}$ and $2 u^{8}$, than the six originally proposed when compared with the basic repleta standard. Nevertheless, these two inversions, overlooked in all past studies, are rather small and do not alter greatly the chromosome's morphology. Even more important, they add nothing to the published phylogenies of the repleta group except within the repleta subgroup where they have become fixed. Therefore, in order to avoid unnecessarily changing the published information (otherwise the formulae for the standard sequences of most species, and the maps of chromosome 2 would have to be modified) 
we will continue to designate $\mathrm{Xabc} ; 2 \mathrm{ab} ; 3 \mathrm{~b}$ as the PRIMITIVE I sequence, reserving the use of the $2 t^{8}$ and $2 \mathrm{u}^{8}$ inversions for studies within the repleta subgroup where these inversions did, in fact, arise.

A number of interspecific crosses involving strains of D. mulleri from Great Inagua, D. stalkeri, D. richardsoni (Table 1), and the eight species in the buzzatii and the martensis cluster (Table 2) was attempted in small mass cultures of five or 10 pairs. As many larvae as possible from the $F_{1}$ of each of the 16 interspecific crosses yielding progeny were dissected and their salivary gland chromosomes studied. Each of the 11 species, except $D$. uniseta, was involved in at least one successful cross with another species. Only the polytene chromosomes of the hybrids of the two crosses $D$. starmeri $\times D$. venezolana (Ruiz \& Fontdevila, 1981) and $D$. buzzatii $\times D$. koepferae (Ruiz et al., 1982) had been previously analysed. They were not repeated here.

\section{Results}

The cytogenetic relationships of the 11 species included in this study have been independently investigated in the past: D. stalkeri and D. richardsoni by Wasserman $(1962,1982)$; D. martensis, D. starmeri and D. uniseta by Wasserman \& Koepfer (1979); D. venezolana by Ruiz \& Fontdevila (1981); D. buzzatii and $D$. koepferae by Ruiz et al. (1982); D. serido and $D$. borborema by Wasserman \& Richardson (1987) and Tosi \& Sene (1989); and D. mulleri by Wasserman (1962). This is the first time, however, that all 11 species are simultaneously considered and directly compared in a single study.

All the species included in this analysis have similar basic karyotypes consisting of six chromosome pairs: four pairs of equal-length acrocentric autosomes, one pair of dot autosomes, a long acrocentric $X$ and a metacentric, submetacentric or small acrocentric $\mathrm{Y}$ (Wasserman, 1982; Wasserman et al., 1983; Baimai et al., 1983; Fontdevila et al., 1988). Hence, the chief interspecific differences in the metaphase chromosomes involve the size and shape of the heterochromatic Y chromosome. The karyotype of $D$. serido is quite variable (Baimai et al., 1983). In some populations of this species the dot is replaced by a submetacentric chromosome due to the acquisition of extra heterochromatin in both arms; in others it appears relatively enlarged due to the addition of heterochromatin in one arm.

\section{Inversion 3a, the link to the mulleri complex}

The banding of chromosome 3 of $D$. martensis was directly compared with that of $D$. mulleri by A. Ruiz. It was determined that the inversion fixed in martensis is not identical to $3 \mathrm{a}$ and it is renamed $3 \mathrm{r}^{2}$ (break-points are given below). Inspection of chromosome 3 in $D$. starmeri, D. venezolana and D. uniseta and the analysis of the interspecific hybrids, given below, indicated that the other members of the martensis cluster also have $3 \mathrm{r}^{2}$, and not $3 \mathrm{a}$. This breaks the only cytological link of the martensis cluster and their related species with the mulleri complex.

\section{Salivary gland chromosomes of the interspecific hybrids}

The chromosomes of the $F_{1}$ hybrids produced in 16 different crosses, which amount to 14 interspecific combinations, were observed. A detailed account of the results is given in Appendix A. From these results the following conclusions can be drawn.

The standard chromosome 2 of the stalkeri cluster differs from that of the buzzatii cluster by only a single inversion, $2 z^{7}$. The standard chromosome 2 of the buzzatii cluster differs from that of the martensis cluster by only a single inversion, $2 \mathrm{e}^{2}$. Thus the relationship among the three clusters is straightforward, being one of the following:

Path (a) stalkeri $\rightarrow$ buzzatii $\rightarrow$ martensis; Path (b) martensis $\rightarrow$ buzzatii $\rightarrow$ stalkeri; Path (c) stalkeri $\leftarrow$ buzzatii $\rightarrow$ martensis.

The inversions, per se, do not indicate direction of evolution. However, there is good evidence that PRIMITIVE I is the ancestral sequence of the repleta species group. The standard chromosome 2 of the stalkeri cluster can be derived from chromosome 2 of PRIMITIVE I by two inversions, $2 \mathrm{~m}$ and $2 \mathrm{n}$. The standard chromosome 2 of the martensis cluster can be derived approximately from chromosome 2 of PRIMITIVE I by three inversions, $2 \mathrm{~d}^{2}, 2 \mathrm{~s}^{6}$, and a new inversion, $2 \mathrm{v}^{8}$. The new breakage points for $2 \mathrm{~s}^{6}$ are $\mathrm{F} 2 \mathrm{a}$ and F6a. This is followed by inversion $2 \mathrm{~d}^{2}$ whose break-points are D3c and F3a and by inversion $2 v^{8}$ whose break-points are D3a and G1-. The latter two inversions overlap and follow inversion $2 \mathrm{~s}^{6}$. The standard chromosome 2 of the buzzatii cluster can be derived from chromosome 2 of PRIMITIVE I only by passing through either martensis or stalkeri; buzzatii is, therefore, eliminated as the ancestral cluster of the buzzatii complex.

Thus we see that there are two ways the complex could have evolved from the PRIMITIVE I, either Path (a): PRIMITIVE I to stalkeri $(2 \mathrm{mn})$ to buzzatii $\left(2 \mathrm{mnz}^{7}\right)$ to martensis $\left(2 \mathrm{mnz}^{7} \mathrm{e}^{2}\right)$; or Path (b): PRIMITIVE I to martensis $\left(2 \mathrm{~d}^{2} \mathrm{~s}^{6} \mathrm{v}^{8}\right)$ to buzzatii $\left(2 \mathrm{~d}^{2} \mathrm{~s}^{6} \mathrm{v}^{8} \mathrm{e}^{2}\right)$ to stalkeri $\left(2 d^{2} s^{6} v^{8} e^{2} z^{7}\right)$. The reason for this unusual situation is that the break-points of the inversions are not distri- 
buted at random; only four major pieces of chromosome 2 seem to have been moved by the seven possible inversions. In fact, each of the proposed inversions, $2 \mathrm{~m}, 2 \mathrm{n}, 2 \mathrm{~d}^{2}, 2 \mathrm{~s}^{6}, 2 \mathrm{v}^{8}, 2 \mathrm{z}^{7}$ and $2 \mathrm{e}^{6}$, has one of its break-points in the $\mathrm{F}_{2}$ region, a region consisting of only about six bands. Wasserman (1982), not being aware of the relationship of stalkeri to buzzatii, had previously chosen Path (b) as the direction of evolution because it was the most parsimonious. However, with the inclusion of the stalkeri cluster, Path (a) becomes the most parsimonious, there being only a total of four inversions needed to go from PRIMITIVE I to the martensis standard chromosome 2 via Path (a), while five inversions are required to go from PRIMITIVE I to the stalkeri standard via Path (b). Further evidence indicating that the stalkeri cluster is ancestral is the fact that their X, 3, 4 and 5 chromosomes appear to have not changed from those of PRIMITIVE I, while the martensis cluster is homozygous for four new inversions, $\mathrm{Xj}, 3 \mathrm{w}, 3 \mathrm{r}^{2}$ and $5 \mathrm{~d}^{2}$. Given the data available at this time, we choose Path (a) as the most probable evolutionary path (see Fig. 1). Following is a description of the salivary gland chromosomes of the species, given the new phylogeny.

\section{Salivary gland chromosomes of the stalkeri species cluster}

The four stocks of $D$. stalkeri were homozygous for the same arrangements in all chromosomes, i.e. neither polymorphism nor interpopulation differences were found (Table 1). These arrangements differ from PRIMITIVE I by three paracentric inversions, namely $2 \mathrm{~m}, 2 \mathrm{n}$, and $2 \mathrm{l}$ (Wasserman, 1962). Inversions $2 \mathrm{~m}$ and $2 \mathrm{n}$ are arranged in tandem and apparently share the middle break-point while inversion 21 follows and overlaps $2 \mathrm{~m}$ (Fig. 2). The map of the standard chromosome 2 of $D$. stalkeri is shown in Fig. 3a.

The standard sequence of $D$. richardsoni differs from the PRIMITIVE I by four inversions, $2 \mathrm{~m}, 2 \mathrm{n}, 2 \mathrm{w}^{7}$ and $2 y^{7}$ (Table 1). Thus, chromosome 2 of D. richardsoni has evolved from the PRIMITIVE I sequence by the fixation of two of the inversions also fixed in D. stalkeri, $2 \mathrm{~m}$ and $2 \mathrm{n}$, plus another two speciesspecific inversions, $2 \mathrm{w}^{7}$ and $2 \mathrm{y}^{7}$, one of which is included within the other and shares with it one breakpoint (Fig. 2). The four stocks of $D$. richardsoni from Montserrat Island were homozygous for the standard chromosome 2 of the species while the four stocks from Tortola and Virgin Gorda contained a polymorphic inversion, $2 \mathrm{p}^{8}$ (Fig. $3 \mathrm{~B}$ ). One larva of one stock from Tortola was heterozygous for another inversion on the same chromosome, $2 q^{8}$, included within the $2 \mathrm{p}^{8}$ segment and with break-points E5e-D $3 \mathrm{e}$.

\section{Salivary gland chromosomes of the buzzatii species cluster}

The standard sequence of $D$. buzzatii differs from the PRIMITIVE I sequence by four inversions, $5 \mathrm{~g}, 2 \mathrm{~m}, 2 \mathrm{n}$ and a new inversion, $2 \mathrm{z}^{7}$ (Table 2 ). This makes the standard chromosome 2 of D. buzzatii as $2 \mathrm{abmnz}^{7}$ (Fig. 2). The chromosome map for this newer interpretation of the standard arrangement of the $D$. buzzatii chromosome 2 is shown in Fig. $3 \mathrm{C}$ and the positions of the common polymorphic inversions are given in Fig. $3 \mathrm{C}$ and $\mathrm{D}$.

The buzzatii chromosome 2 is the standard for the buzzatii cluster. Each of the other three species in the buzzatii cluster, D. koepferae, $D$. serido and $D$. borborema, has in addition to the buzzatii chromosome one further fixed inversion in chromosome $2: 2 j^{9}$ is fixed in D. koepferae, $2 \mathrm{x}^{7}$ in $D$. serido and $2 \mathrm{e}^{8}$ in $D$. borborema. Inversion $2 \mathrm{e}^{8}$ is distally located while

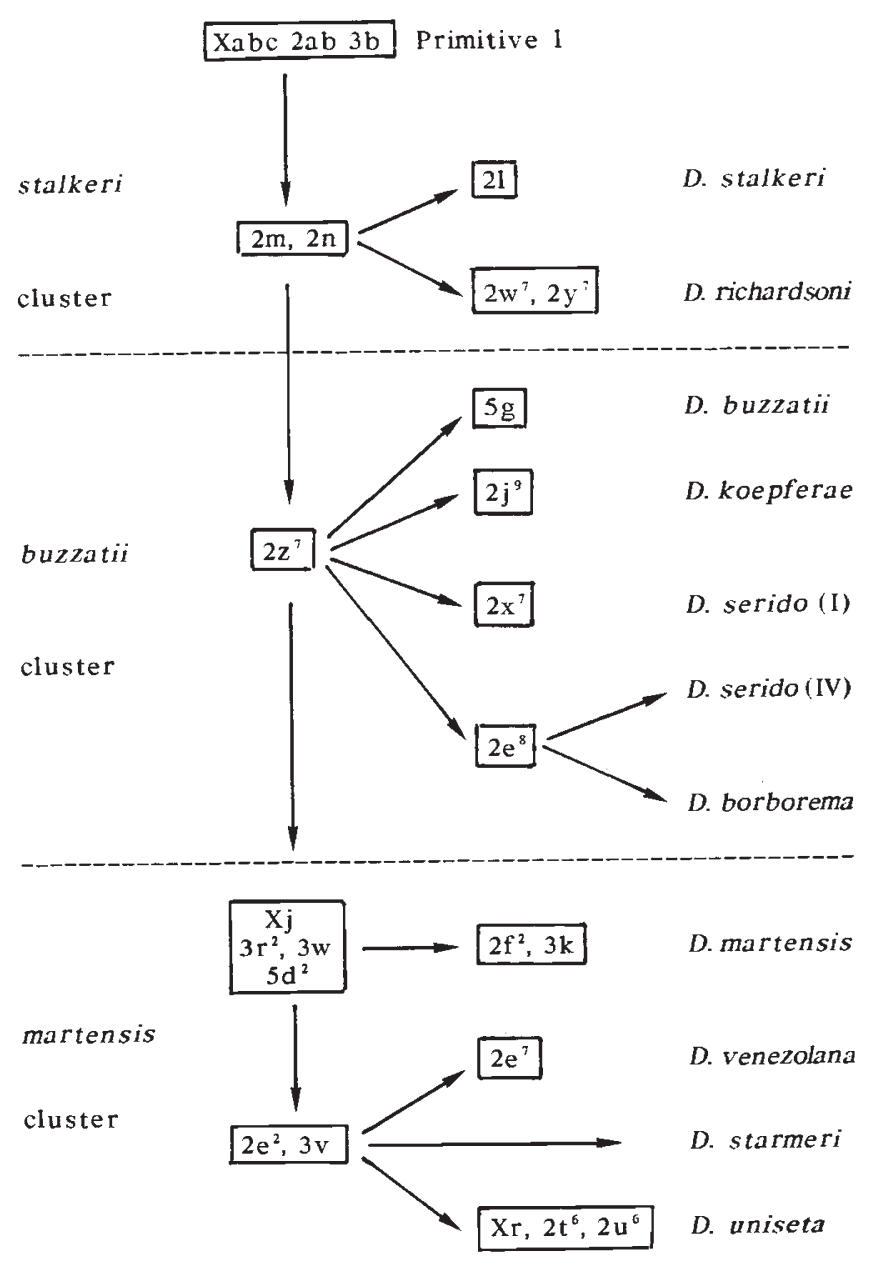

Fig. 1 Chromosomal evolution of the buzzatii species complex. Only the paracentric inversions homozygous in each of the species are shown. 


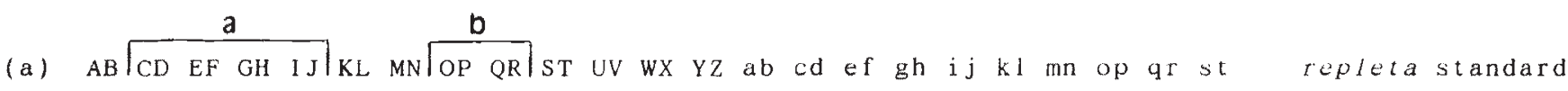

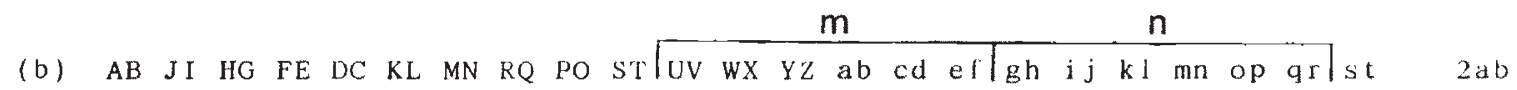

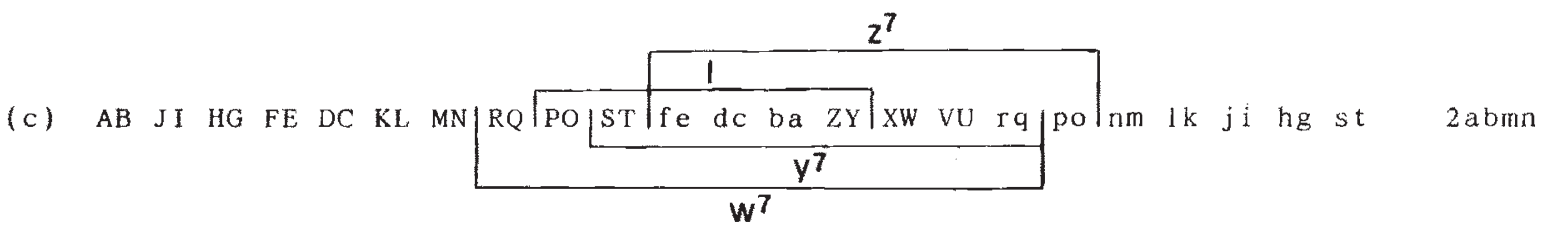

(d) AB JI HG FE DC KL MN RQ YZ ab cd ef TS OP XW VU rq po nm lk ji hg st 2 abmnl

(e) AB JI HG FE DC KL MN ST fe dc ba ZY XW VU rq OP QR po nm lk ji hg st $2 \mathrm{abmnw}^{7} \mathrm{y}^{7}$

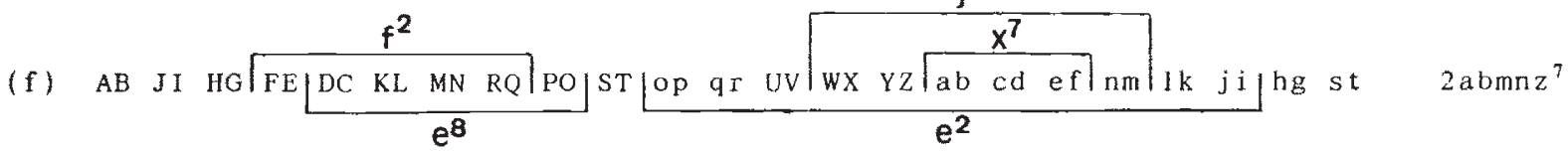

(g) $A B$ JI HG FE OP QR NM LK CD ST op qr UV WX YZ ab cd ef nm lk ji hg st $2 \mathrm{sbmnz}^{7} \mathrm{e}^{8}$

(h) AB JI HG FE DC KL MN RQ PO ST op qr UV WX YZ fe de ba nm lk ji hg st 2 abmnz ${ }^{7} \mathrm{X}^{7}$

(i) AB JI HG FE DC KL MN RQ PO ST op qr uV mn fe de ba ZY XW lk ji hg st $2 \mathrm{abmnz}^{7} \mathrm{j}^{9}$

(j) AB JI HG QR NM LK CD EF PO ST op qr UV WX YZ ab ed ef nm. $1 \mathrm{k}$ ji hg st $2 \mathrm{abmnz} \mathrm{f}^{2}$

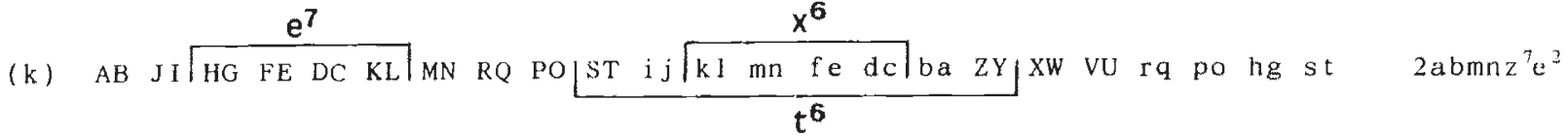

(1) $\mathrm{AB} J \mathrm{LK} \mathrm{CD}$ EF GH MN RQ PO ST ij kI mn fe dc ba $Z Y$ XW VU rq po hg st $2 a b m n z^{7} \mathrm{e}^{2} \mathrm{e}^{7}$

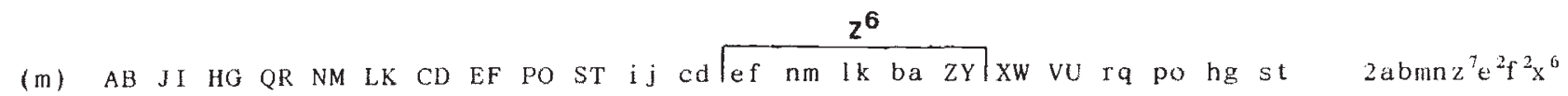

(n) AB JI HG QR NM LK CD EF PO ST ij cd YZ ab kl mn fe XW VU rq po hg st $2 a b m n z^{7} \mathrm{e}^{2} \mathrm{f}^{2} \mathrm{x}^{6} \mathrm{z}^{6}$

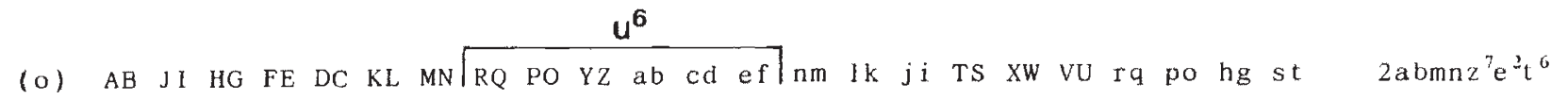

(p) AB JI HG FE DC KL MN fe dc ba ZY OP QR nm lk ji TS XW VU rq po hg st $2 \mathrm{~s}^{2} \mathrm{~b}^{7} \mathrm{e}^{2} \mathrm{t}^{6} \mathrm{u}^{6}$

Fig. 2 Evolution of chromosome 2 in the buzzatii complex species. Each letter pair represents an unbroken chromosome segment of the D. repleta map of Wharton (1942) and the key is given in Appendix B. (a) D. repleta sequence showing the positions of $2 \mathrm{a}$ and $2 \mathrm{~b}$; (b) $2 \mathrm{ab}$, ancestral sequence of the repleta species group, showing the break-points of $2 \mathrm{~m}$ and $2 \mathrm{n}$; (c) 2abmn, ancestral sequence of the buzzatii species complex, showing the break-points of 21 (fixed in D. stalkeri), $2 \mathrm{w}^{7}$ and $2 \mathrm{y}^{7}$ (fixed in $D$. richardsoni), and $2 \mathrm{z}^{7}$ (fixed in the other species); (d) $2 \mathrm{abmnl}$, standard sequence of D. stalkeri; (e) $2 \mathrm{abmnw}^{7} \mathrm{y}^{7}$, standard sequence of $D$. richardsoni; (f) $2 \mathrm{abmnz}^{7}$, standard sequence of $D$. buzzatii showing the break-points of $2 \mathrm{e}^{8}$ (fixed in $D$. borborema), $2 \mathrm{x}^{7}$ (fixed in D. serido), $2 \mathrm{j}^{9}$ (fixed in D. keopferae), $2 \mathrm{f}^{2}$ (fixed in $D$. martensis and polymorphic in $D$. starmeri), and $2 \mathrm{e}^{2}$ (fixed in D. starmeri, D. venezolana and D. uniseta); (g) $2 \mathrm{abmnz}^{7} \mathrm{e}^{8}$, standard sequence of D. borborema; (h) $2 \mathrm{abmnz} \mathrm{x}^{7}$, standard sequence of $D$. serido; (i) $2 \mathrm{abmnz}^{7} \mathrm{j}^{9}$, standard sequence of $D$. koepferae; (j) $2 \mathrm{abmnz} \mathrm{f}^{7}$, standard sequence of $D$. martensis; (k) $2 \mathrm{abmnz}^{7} \mathrm{e}^{2}$, standard (hypothetical) sequence of D. starmeri with the break-points of $2 \mathrm{e}^{7}$ (fixed in $D$. venezolana and polymorphic in D. starmeri), $2 \mathrm{x}^{6}$ (polymorphic in D. starmeri) and $2 \mathrm{t}^{6}$ (fixed in D. uniseta and polymorphic in $D$. starmeri); ( 1 ) $2 \mathrm{abmnz} \mathrm{z}^{2} \mathrm{e}^{7}$, standard sequence of $D$. venezolana which is also found in $D$. starmeri; $(\mathrm{m}) 2 \mathrm{abmnz} \mathrm{e}^{7} \mathrm{e}^{2} \mathrm{f}^{2} \mathrm{x}^{6}$, sequence ancestral to many of the arrangements present now in D. starmeri, with the break-points of $2 z^{6}$ (polymorphic in D. starmeri); ( $\mathrm{n}$ ) $2 \mathrm{abmn} \mathrm{z}^{7} \mathrm{e}^{2} \mathrm{f}^{2} \mathrm{x}^{6} \mathrm{z}^{6}$, chromosome arrangement widespread now in D. starmeri; $(\mathrm{o}) 2 \mathrm{abmnz} \mathrm{z}^{7} \mathrm{t}^{6}$, sequence ancestral to $D$. uniseta with the break-points of $2 \mathrm{u}^{6}$ (fixed in D. uniseta); (p) $2 a b m n z^{7} \mathrm{e}^{2} \mathrm{t}^{6} \mathrm{u}^{6}$, standard arrangement of D. uniseta. 
inversions $2 \mathrm{j}^{9}$ and $2 \mathrm{x}^{7}$ occupy a similar proximal region (Fig. 2). The standard sequence of $D$. serido is Xabc;2abmnz $\mathrm{X}^{7} ; 3 \mathrm{~b}$, while that of $D$. borborema is Xabc;2abmnz $\mathrm{e}^{8} ; 3 \mathrm{~b}$ (Table 2). The D. serido stock analysed in this study was homozygous for one further inversion, $2 \mathrm{a}^{8}$, but this inversion is only polymorphic in the species since it coexists with the standard arrangement in other stocks (Wasserman \& Richardson, 1987). Likewise, the $D$. borborema stock analysed here was fixed for one further inversion, $2 \mathrm{f}^{8}$, which is polymorphic and segregates with the standard arrangement in the two localities investigated thus far (Wasserman \& Richardson, 1987). Figure $3 E$ and $F$ shows the breakpoints of the polymorphic inversions $2 \mathrm{a}^{8}$ and $2 \mathrm{f}^{8}$.

The standard sequence of $D$. koepferae is Xabc;2abmnz $\mathrm{j}^{7} ; 3 \mathrm{~b}$ and was present in one of the stocks from Bolivia (Table 2). In addition, this stock was polymorphic for one inversion in chromosome 2, $2 \mathrm{k}^{9}$. A $D$. koepferae stock from Argentina lacked the standard chromosome 2 but was polymorphic for $2 \mathrm{k}^{9}$ and three other inversions, $21^{9}, 2 \mathrm{~m}^{9}$ and $2 \mathrm{n}^{9}$ (Fig. $3 \mathrm{G}$ and $\mathrm{H}$ ). In addition, it was homozygous for one inversion in each of the three other major autosomes (Table 2 ; Ruiz et al., 1982).

\section{Salivary gland chromosomes of the martensis cluster species}

The standard sequence of $D$. martensis differs from PRIMITIVE I by nine inversions and is Xabcj;2abmnz $\mathrm{f}^{7}{ }^{2} ; 3 \mathrm{bkwr}^{2} ; 4 ; 5 \mathrm{~d}^{2}$ (Table 2). The map of the standard chromosome 2 is shown in Fig. 3I. Inversions $3 \mathrm{w}$ and $5 \mathrm{~d}^{2}$ had been previously overlooked (Wasserman \& Koepfer, 1979). The break-points of $3 r^{2}$ and the new inversion $3 w$ are given in Fig. 4 which depicts the evolution of chromosome 3 in the martensis cluster. Approximate break-points for $5 \mathrm{~d}^{2}$ are E1a-F1a.

D. starmeri is cytologically the most complex and variable of all the analysed species. Its standard arrangements differ from PRIMITIVE $I$ by nine inversions, seven of which, $\mathrm{Xj}, 2 \mathrm{~m}, 2 \mathrm{n}, 2 \mathrm{z}^{7}, 3 \mathrm{r}^{2}, 3 \mathrm{w}$ and $5 \mathrm{~d}^{2}$, are also fixed in $D$. martensis as well as in $D$. uniseta and $D$. venezolana and two, $2 \mathrm{e}^{2}$ and $3 \mathrm{v}$, are fixed in the latter two species but absent in $D$. martensis (Fig. 1). Thus, its standard sequence is Xabcj;2abmnz $\mathrm{e}^{2} ; 3 \mathrm{br}^{2} \mathrm{wv} ; 4 ; 5 \mathrm{~d}^{2}$ (Table 2). The standard chromosome 2 of $D$. starmeri is hypothetical, i.e. has never been found (Wasserman \& Koepfer, 1979; Ruiz \& Fontdevila, 1981) nor was it present in the stock studied here. This stock contained two different arrangements derived from the standard chromosome 2 , one by the addition of inversion $2 \mathrm{e}^{7}$ and the other one by the addition of three inversions, $2 f^{2} x^{6} z^{6}$ (Table
2). Inversions $2 \mathrm{e}^{7}$ and $2 \mathrm{f}^{2}$ are overlapping and mutually exclusive, whereas inversions $2 \mathrm{x}^{6}$ and $2 \mathrm{z}^{6}$ are also overlapping but independent from $2 \mathrm{f}^{2}$ and $2 \mathrm{e}^{7}$ (Figs 2 and $3 \mathrm{~J}$ and $\mathrm{K}$ ). Thus, in principle recombination may be possible between the two chromosomes. No recombinants have ever been observed, however, in this or other studies. The stock of $D$. starmeri was also polymorphic for inversion Xq. Therefore, its chromosomal constitution was typical of the western race of $D$. starmeri (Wasserman \& Koepfer, 1979; Ruiz \& Fontdevila, 1981).

The standard sequences of $D$. venezolana and $D$. uniseta differ from PRIMITIVE I by 10 and 12 inversions, respectively (Table 2 ). That of $D$. venezolana falls entirely within the limits of the chromosomal variation found in D. starmeri (Ruiz \& Fontdevila, 1981) and can be written as Xabcj; $2 \mathrm{abmnz} \mathrm{e}^{7} \mathrm{e}^{7} ; 3 \mathrm{br}^{2} \mathrm{wv} ; 4 ; 5 \mathrm{~d}^{2}$ (Table 2). D. uniseta is homozygous for two species-specific inversions, $\mathrm{Xr}$ and $2 \mathrm{u}^{6}$, in addition to $2 \mathrm{t}^{6}$, which is polymorphic in D. starmeri (Fig. 2). Thus, the standard sequence of $D$. uniseta is Xabcjr;2abmnz $\mathrm{e}^{2} \mathrm{t}^{6} \mathrm{u}^{6} ; 3 \mathrm{br}^{2} \mathrm{wv} ; 4 ; 5 \mathrm{~d}^{2}$ (Table 2). Maps of the chromosome 2 standard arrangements of $D$. venezolana and $D$. uniseta are shown in Fig. $3 \mathrm{~J}$ and $\mathrm{L}$, respectively.

\section{Discussion}

Figure 1 shows the chromosomal evolution of the 10 species included in the buzzatii species complex and Table 3 summarizes all previous cytological information on these species as well as the new information presented in this paper. This new information modifies our concepts of the relationships and evolution of some of the clusters in this part of the mulleri subgroup. The lack of $3 \mathrm{a}$ in the martensis cluster separates the South American clusters from the rest of the mulleri complex. It also eliminates a number of shared, homozygous inversions. The mulleri complex can now be defined as consisting of those species that are homozygous for $2 \mathrm{~g}$ and $3 \mathrm{a}$, while the buzzatii complex species are homozygous for $2 \mathrm{~m}$ and $2 \mathrm{n}$.

The fact that the two complexes are phylogenetically very close to each other is nevertheless attested to by the amount of intercomplex hybridization which can take place in the laboratory. $D$. buzzatii was known to cross with several species of the mulleri complex. Patterson \& Alexander (1952) reported that $D$. buzzatii females produce $\mathrm{F}_{1}$ larvae when crossed with $D$. wheeleri; while $D$. buzzatii males produce larvae with $D$. arizonae, sterile $\mathrm{F}_{1}$ females with $D$. wheeleri, and sterile $F_{1}$ males and females with $D$. mulleri. We carried out a series of intercomplex crosses with $D$. mulleri (stock ORV 21 from Great Inagua, the 


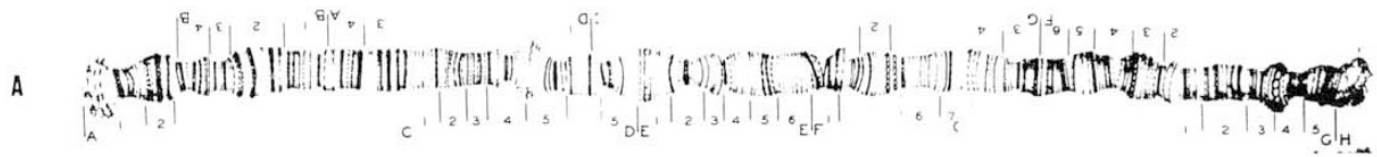

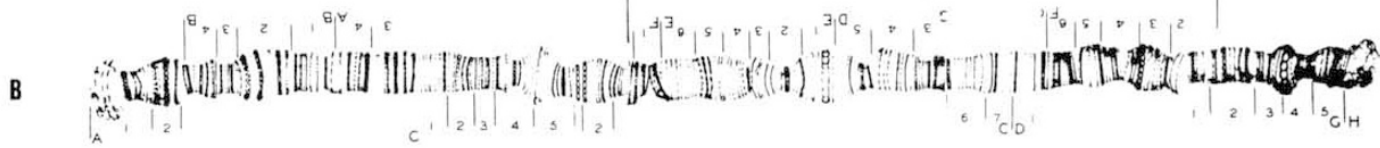

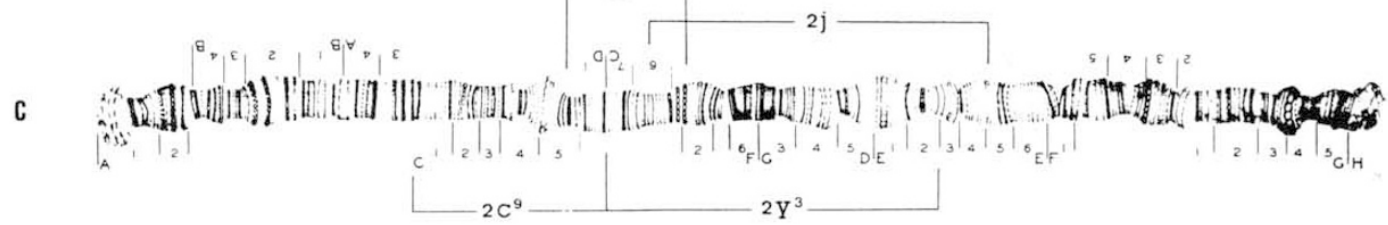

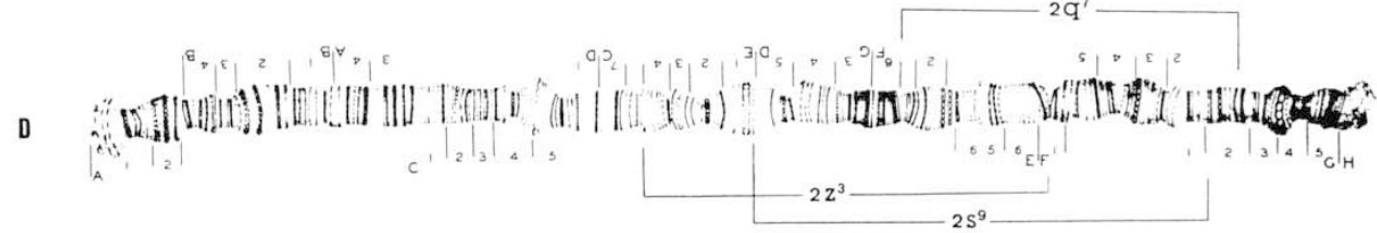

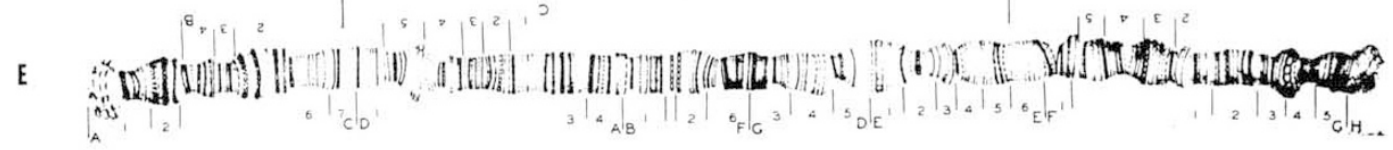

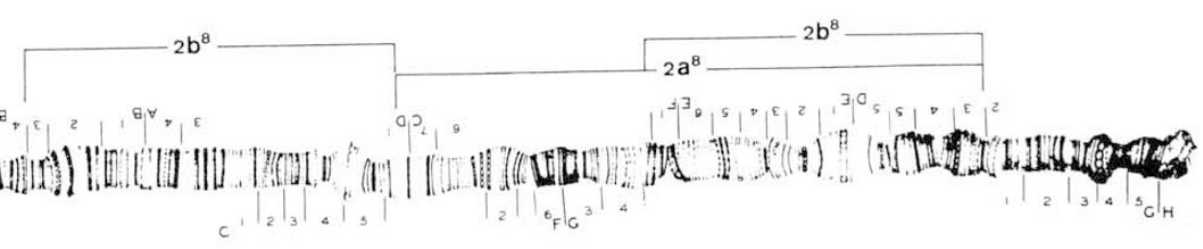

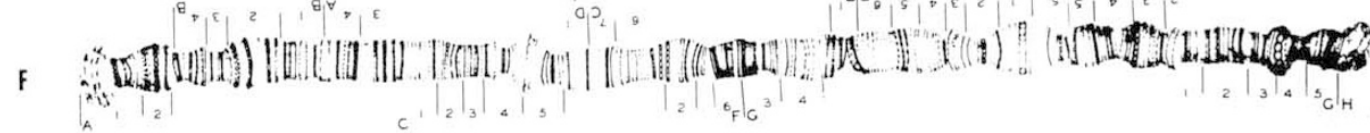

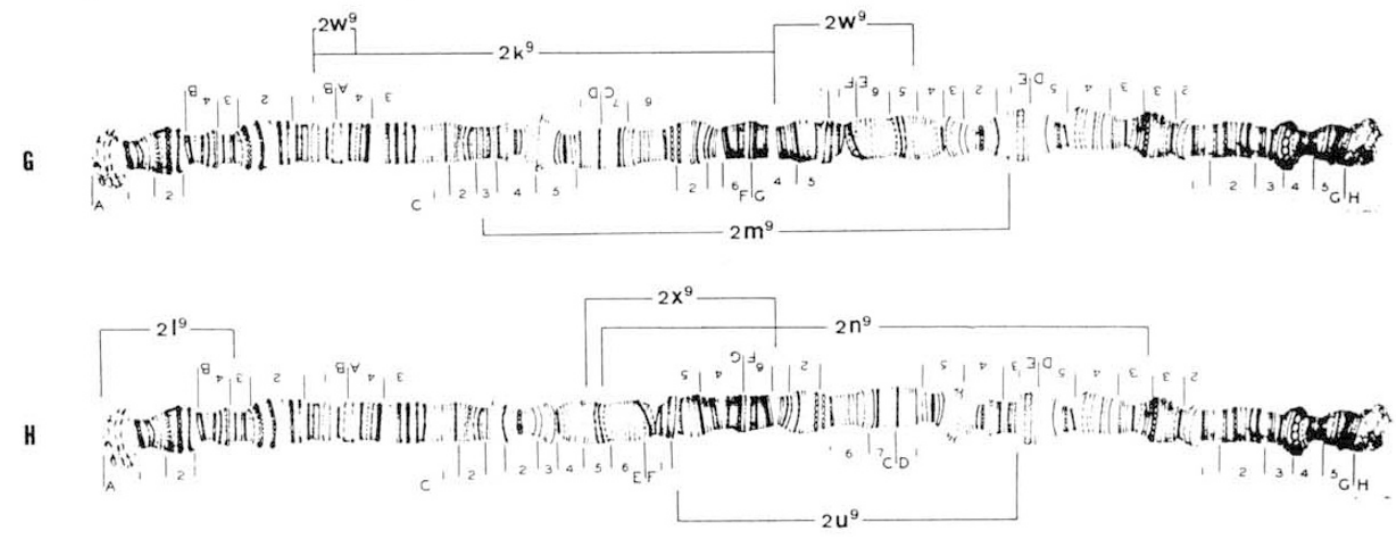

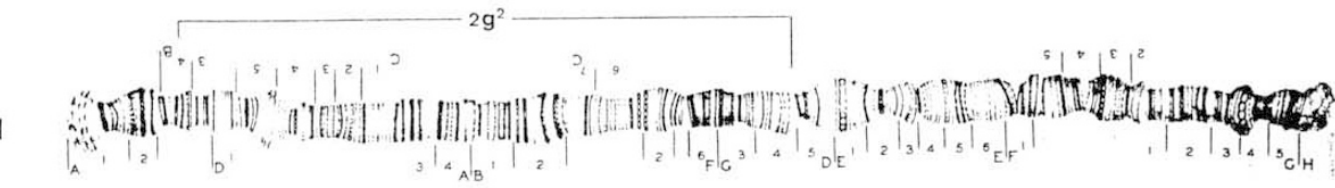




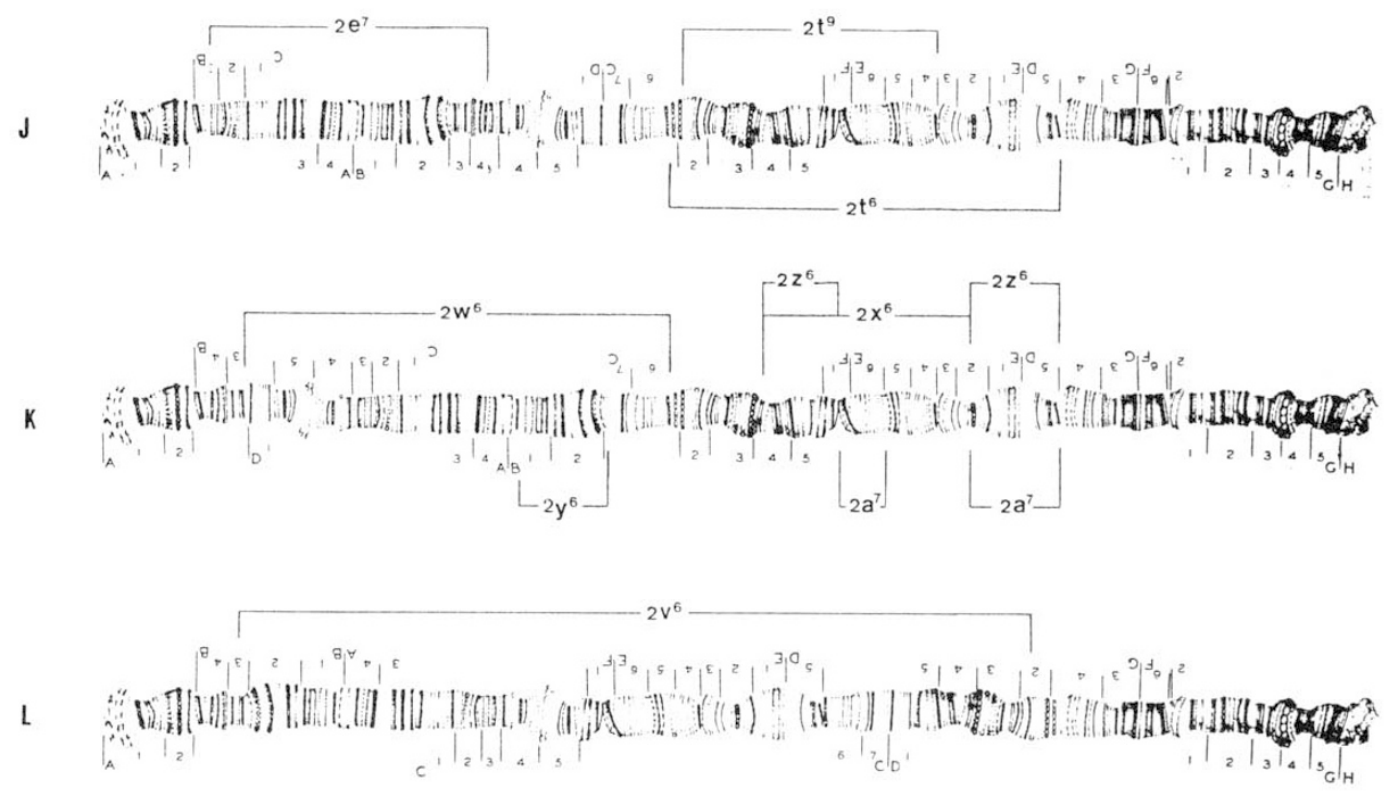

Fig. 3 (this page and opposite) Chromosome 2 maps of the D. buzzatii complex species. Each map has been produced rearranging the $D$. repleta map of Wharton (1942) according to the changes shown in Figs 1 and 2. A. 2abmnI, standard sequence of $D$.

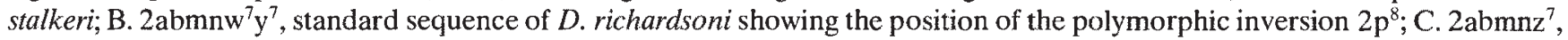
standard sequence of $D$. buzzatii showing the break-points of $2 \mathrm{j}, 2 \mathrm{c}^{9}, 2 \mathrm{y}^{3}$ and $2 \mathrm{r}^{9} ;$ D. $2 \mathrm{abmnz} \mathrm{z}^{7}$, widespread chromosome arrangement of $D$. buzzatii with the break-points of $2 \mathrm{z}^{3}, 2 \mathrm{q}^{7}, 2 \mathrm{~s}^{9}$; E. 2abmnz $\mathrm{e}^{7}$, standard sequence of $D$. borborema with the break-points of $2 \mathrm{f}^{8} ; \mathrm{F}$. 2abmnz $\mathrm{x}^{7}$, standard sequence of $D$. serido with the break-points of $2 \mathrm{a}^{8}$ and $2 \mathrm{~b}^{8}$ (that follows and overlaps $\left.2 \mathrm{a}^{8}\right)$; G. $2 \mathrm{abmnz} \mathrm{j}^{9}$, standard sequence of D. koepferae with the break-points of $2 \mathrm{k}^{9}, 2 \mathrm{w}^{9}$ (that follows and overlaps $2 \mathrm{k}^{9}$ ) and $2 \mathrm{~m}^{9}$; H. $2 \mathrm{abmnz}^{7} \mathrm{j}^{9} \mathrm{~m}^{9}$, chromosome arrangement of $D$. koepferae showing the break-points of inversions $2 \mathrm{l}^{9}, 2 \mathrm{x}^{9}, 2 \mathrm{n}^{9}$ and $2 \mathrm{u}^{9} ; \mathrm{I}$. $2 \mathrm{abmnz} \mathrm{f}^{7}$, standard arrangement of $D$. martensis with the break-points of $2 \mathrm{~g}^{2} ; \mathrm{J} .2 \mathrm{abmnz} \mathrm{e}^{7} \mathrm{e}^{7}$, standard sequence of $D$. venezolana which is also found in D. starmeri showing the positions of $2 \mathrm{t}^{9}$ (polymorphic in D. venezolana) and $2 \mathrm{t}^{6}$ (polymorphic in $D$. starmeri ; K. $2 \mathrm{abmnz} \mathrm{z}^{7} \mathrm{e}^{2} \mathrm{f}^{2}$, sequence ancestral to some of the arrangements of D. starmeri with the break-points of $2 \mathrm{w}^{6}, 2 \mathrm{x}^{6}, 2 \mathrm{z}^{6}$ (which follows and overlaps $2 x^{6}$ ), $2 a^{7}$ (which follows and overlaps $2 x^{6}$ and $2 z^{6}$ ) and $2 y^{6} ;$ L. $2 a b m n z^{7} e^{2} f^{2} x^{6} z^{6}$, standard sequence of $D$. uniseta with the break-points of $2 \mathrm{v}^{6}$.

Fig. 4 Evolution of chromosome 3 in the buzzatii complex species. Each letter pair represents an unbroken chromosome segment of the $D$, repleta map of Wharton (1942) and the key is given in Appendix B. (a) D. repleta sequence showing the position of $3 b$; (b) $3 \mathrm{~b}$, ancestral sequence of the repleta species group, showing the breakpoints of $3 r^{2}$ and $3 w$; (c) $3 b r^{2} w$, ancestral sequence of the martensis cluster species with the break-points of inversions $3 \mathrm{k}$ (fixed in $D$, martensis) and $3 \mathrm{v}$ (fixed in D. starmeri, D. venezolana and D. uniseta); (d) $3 \mathrm{br}{ }^{2} \mathrm{wk}$, standard sequence of $D$. martensis; (e) $3 \mathrm{br}^{2} \mathrm{wv}$, standard sequence of $D$. starmeri, $D$. venezolana and $D$. uniseta.
(a) $A B C D$ EF
repleta standard
(b) $\frac{r^{2}}{C D}$ EF LK JI HG MN $\frac{W}{O P}$ QR ST
$3 b$

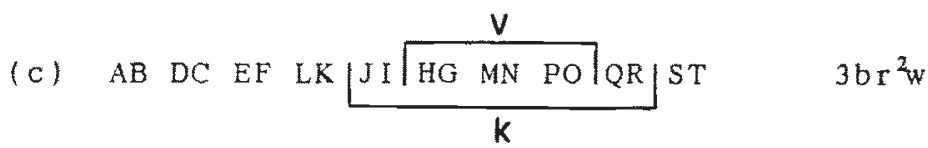
(d) $A B$ DC EF LK RQ OP NM GH IJ ST 3br ${ }^{2} w k$
(e) AB DC EF LK JI OP NM GH QR ST $3 \mathrm{br}{ }^{2} W V$ 
Table 3 Chromosomal constitution of the buzzatii complex species*

\begin{tabular}{|c|c|c|c|c|c|c|c|}
\hline \multirow[b]{2}{*}{$\begin{array}{l}\text { Drosophila } \\
\text { species }\end{array}$} & \multicolumn{5}{|c|}{ Fixed inversions } & \multicolumn{2}{|c|}{ Intraspecific variation } \\
\hline & Xabc & 2abmn & $3 b$ & 4 & 5 & $\begin{array}{l}\text { Polymorphic } \\
\text { inversions } \dagger\end{array}$ & $\begin{array}{l}\text { Rare } \\
\text { endemics }\end{array}$ \\
\hline stalkeri & + & 1 & + & + & + & & \\
\hline richardsoni & + & $w^{7} y^{7}$ & + & + & + & $2 p^{8}$ & $2 q^{8}$ \\
\hline buzzatii & + & $z^{7}$ & + & + & $\mathrm{g}$ & $\begin{array}{l}2 \mathrm{j}, 2 \mathrm{jz} z^{3}, \\
2 \mathrm{jq}^{7}, 2 \mathrm{jc}^{9}, 2 \mathrm{y}^{3}, \\
2 \mathrm{r}^{9}, 2 \mathrm{js} \mathrm{s}^{9}, 4 \mathrm{~s}\end{array}$ & $\begin{array}{l}2 \mathrm{e}^{9} \mathrm{f}^{9}, 2 \mathrm{~g}^{9} \\
2 \mathrm{ji}^{9}, 2 \mathrm{jc} \mathrm{c}^{9} \mathrm{~d}^{9} \\
2 \mathrm{jh}^{9}, 3 \mathrm{j}^{2}, 5 \mathrm{c}^{2}\end{array}$ \\
\hline borborema & + & $z^{7} e^{8}$ & + & + & + & $2 \mathrm{f}^{8}$ & $2 \mathrm{f}^{8} \mathrm{~g}^{8}, 2 \mathrm{f}^{8} \mathrm{~h}^{8}$ \\
\hline serido $(\mathbf{I})$ & + & $z^{7} x^{7}$ & + & + & + & $2 a^{8}, 2 a^{8} b^{8}$ & $2 c^{8}, 2 d^{8}$ \\
\hline serido (IV) & + & $z^{7} e^{8}$ & + & + & + & '2a' & \\
\hline koepferae & + & $z^{7} \mathbf{j}^{9}$ & + & + & + & $\begin{array}{l}2 \mathrm{k}^{9}, 2 \mathrm{k}^{9} \mathrm{w}^{9}, \\
2 \mathrm{~m}^{9}, 2 \mathrm{~m}^{9} \mathrm{n}^{9}, \\
2 \mathrm{l}^{9}, 2 \mathrm{~m}^{9} \mathrm{x}^{9}, \\
2 \mathrm{l}^{9} \mathrm{~m}^{9} \mathrm{n}^{9} \\
2 \mathrm{~m}^{9} \mathrm{u}^{9}, " 2 \mathrm{~d} ", \\
" 2 \mathrm{e} ", 3 \mathrm{k}^{2}, 4 \mathrm{~m}, \\
5 \mathrm{w}, " 5 \mathrm{a} "\end{array}$ & $2 m^{9} v^{9}$ \\
\hline martensis & j & $z^{7} f^{2}$ & $r^{2} w k$ & + & $d^{2}$ & $2 g^{2}$ & $2 g^{2} o^{9}, 2 g^{2} p^{9}$ \\
\hline starmeri & $\mathrm{j}$ & $z^{7} e^{2}$ & $r^{2} w V$ & + & $\mathrm{d}^{2}$ & $\begin{array}{l}X q, X q s, \\
2 \mathrm{e}^{7}, 2 \mathrm{e}^{7} t^{6}, \\
2 \mathrm{f}^{2} \mathrm{x}^{6} z^{6}, \\
2 \mathrm{f}^{2} \mathrm{x}^{6} \mathbf{w}^{6}, \\
2 \mathrm{f}^{2} \mathrm{x}^{6} \mathrm{z}^{6} \mathrm{y}^{6}, \\
2 \mathrm{f}^{2} \mathrm{x}^{6} \mathrm{z}^{6} \mathrm{a}^{7}, \\
2 \mathrm{f}^{2} \mathrm{x}^{6} \mathrm{z}^{6} \mathrm{y}^{6} \mathrm{a}^{7}, \\
3 \mathrm{a}^{2}, 3 \mathrm{z}, 3 \mathrm{zy}, \\
5 \mathrm{q}\end{array}$ & $\begin{array}{l}\text { Xqy, } 2 \mathrm{e}^{7} t^{6} \mathrm{q}^{9}, \\
2 \mathrm{e}^{7}, \mathrm{r}^{7}, 2 \mathrm{e}^{7} \mathrm{~b}^{7} \\
2 \mathrm{f}^{2} \mathrm{x}^{6} \mathrm{z}^{6} \mathrm{y}^{6} \mathrm{a}^{7} \mathrm{c}^{7} \\
3 \mathrm{e}^{2}\end{array}$ \\
\hline venezolana & $\mathrm{j}$ & $z^{7} e^{2} e^{7}$ & $r^{2} w V$ & + & $d^{2}$ & $2 t^{9}$ & \\
\hline uniseta & $\mathrm{jr}$ & $z^{7} e^{2} t^{6} u^{6}$ & $r^{2} w v$ & + & $d^{2}$ & $2 v^{6}$ & \\
\hline
\end{tabular}

*Sources: Wasserman \& Koepfer, 1979; Ruiz \& Fontdevila, 1981; Ruiz et al., 1982;

Ruiz et al., 1984; Barker et al., 1985; Wasserman \& Richardson, 1987; Tosi \& Sene, 1989; Fontdevila et al., 1988; unpublished data.

†Only those inversions found in at least two different localities are considered polymorphic.

Bahamas). Females of this D. mulleri strain produced third instar larvae when crossed to males of D. buzzatii, $D$. martensis and D. venezolana (see Appendix A). On the other hand, males of $D$. mulleri produced larvae when crossed to $D$. borborema females but the larvae died in the first or second instar stage and could not be cytologically analysed. All crosses between $D$. mulleri and either D. stalkeri, D. richardsoni, or D. uniseta were unsuccessful. This high level of intercomplex mating is very unusual considering the fact that many species within the mulleri complex produce no interspecific hybrid offspring when exposed to members of their own complex. Moreover, the species in the buzzatii cluster seem to be more amenable to mating with the mulleri complex species than are the species in the D. stalkeri cluster which are supposed to be more primitive and therefore more closely related to the mulleri complex than are the buzzatii cluster species. A possible explanation for this paradox is that $D$. stalkeri and $D$. richardsoni are sympatric with several species of the mulleri complex (Wasserman \& Wasserman, 1992) and thus there has been the opportunity for character displacement in sexual isolation.

It is not easy to fit the cytological phylogeny depicted in Fig. 1 with the geographical distribution of the species. The three clusters of the buzzatii complex are allopatric. The cytologically most primitive, stalkeri, is limited to the Caribbean Islands and Florida; the most advanced, martensis, has an intermediate distribution and is found in Venezuela and 
Colombia; while the buzzatii cluster is known from Brazil, Argentina, and Bolivia. This situation is somewhat similar to that found by Heed \& Russell (1971) in the cardini group, where populations and species with a central distribution are cytologically derived while those in the margins are more conservative. A possible scenario for the evolution of the buzzatii complex is that the ancestor lived in the general region now occupied by the martensis cluster. There was an early invasion of the Caribbean Islands by $2 \mathrm{mn}$ forms which evolved into the stalkeri cluster. A later invasion of Brazil by $2 \mathrm{mnz}^{7}$ forms led to the buzzatii cluster whereas the central area continued to evolve and is now the martensis cluster. As was suggested in the previously published phylogenies (Wasserman, 1982), the species $D$. martensis still occupies an intermediate step between the buzzatii cluster and the rest of the martensis cluster.

Our ideas as to the evolution of the species within the clusters have not changed. $D$. richardsoni and $D$. stalkeri appear to be allopatric species, both having arisen from the $2 \mathrm{mn}$ ancestral migrant. The cytological evolution of the martensis cluster is essentially as was depicted by Wasserman \& Koepfer (1979). The only difference is that the direction of evolution from the species $D$. martensis to $D$. buzzatii should be reversed. The ancestor of the martensis cluster appears to have been a highly polymorphic form which has evolved into the present-day D. starmeri. The other species split off from this ancestor, each fixing its own inversions, many of which have remained polymorphic in D. starmeri. This scenario suffers from the fact that the derived species are not peripherally located to the central polymorphic species. The four species are virtually completely sympatric and there is no present-day evidence of allopatry in the martensis cluster.

Our knowledge of the buzzatii cluster is fragmentary. The way $D$. serido has been treated in Fig. 1 and Table 3 deserves a comment. $D$. serido is a superspecies which consists of many semi-isolated populations ranging from the Caatinga in northeastern Brazil to the Monte in northwestern Argentina (Sene et al., 1982, 1988; Ruiz et al., 1982; Fontdevila et al., 1988). From the point of view of the salivary gland chromosomes, the populations hitherto studied have been classified by Tosi \& Sene (1989) into four chromosomal types. Type $I$ is found in the Brazilian Caatinga and include the type locality of the species as well as the localities investigated by Wasserman \& Richardson (1987) and that studied here. Type III includes the populations of the Monte and western Chaco in Argentina. These populations, first analysed by Ruiz et al. (1982) who called them Argentinian D. serido, were later described as a separate species, under the name of
D. koepferae, by Fontdevila et al. (1988). The populations found in Bolivia also belong to D. koepferae as they are fully fertile with those in northwestern Argentina. Type II include the localities in the eastern Chaco in Argentina. According to Tosi \& Sene (1989) these populations are fixed for the $2 \mathrm{j}^{9}$ inversion, are polymorphic for one inversion on chromosome 5 , which they call ' $5 \mathrm{a}$ ', and are heterozygous on chromosome 2 for two other inversions, ' $2 \mathrm{~d}$ ' and ' $2 \mathrm{e}$ '. We have included these populations in $D$. koepferae based on the observation that they are fixed for the $2 j^{9}$ inversion. However, this inclusion must be considered only tentative until more critical data are obtained. Finally, type IV include the populations in central and western Brazil. Tosi \& Sene (1989) state that these populations are not fixed for the $2 \mathrm{x}^{7}$ inversion, but are homozygous for the $2 \mathrm{e}^{8}$ inversion which is fixed in D. borborema, and polymorphic for another inversion which they call ' $2 a$ '. Since these populations also exhibit a different aedeagus morphology and show reproductive isolation from most other $D$. serido populations, Tosi \& Sene (1989) suggest that they probably represent a separate, and yet undescribed, species.

A total of 84 inversions has occurred during the evolution of the buzzatii species complex (Table 4). Nineteen are homozygous, fixed, inversions. None of them is shared in the sense discussed above. Three inversions are polymorphic in one species but homozygous, fixed, in a sister species. $2 \mathrm{e}^{7}$ is fixed in $D$. venezolana, $2 \mathrm{f}^{2}$ is fixed in $D$. martensis and $2 \mathrm{t}^{6}$ is fixed in D. uniseta; all three inversions are polymorphic in $D$. starmeri. The number of fixed inversions per species varies between 3 in $D$. stalkeri and 12 in D. uniseta, with an average of 6.1 .

Table 4 Number of paracentric inversions homozygous or heterozygous in the evolution of the $D$. buzzatii complex

\begin{tabular}{|c|c|c|c|c|c|c|}
\hline \multirow[b]{2}{*}{ Inversions } & \multicolumn{6}{|c|}{ Chromosome } \\
\hline & $\mathrm{X}$ & 2 & 3 & 4 & 5 & Total \\
\hline Homozygous intercomplex & 0 & 2 & 0 & 0 & 0 & 2 \\
\hline Homozygous intercluster & 1 & 1 & 2 & 0 & 1 & 5 \\
\hline Homozygous intracluster. & 0 & 2 & 1 & 0 & 0 & 3 \\
\hline Homozygous interspecific & 1 & 6 & 1 & 0 & 1 & 9 \\
\hline Homozygous and heterozygous* & 0 & 3 & 0 & 0 & 0 & 3 \\
\hline Intraspecific polymorphism $\dagger$ & 2 & 29 & 4 & 2 & 3 & 40 \\
\hline Rare endemics & 1 & 18 & 2 & 0 & 1 & 22 \\
\hline Total & 5 & 61 & 10 & 2 & 6 & 84 \\
\hline
\end{tabular}

*Inversions which are polymorphic in one species but homozygous, i.e. fixed, in a sister species.

†Only those inversions present in at least two different localities are considered polymorphic. 
Sixty-two inversions are intraspecific variation. No shared heterozygous inversions, i.e. those polymorphic in both of two daughter species, were found. The intraspecific variation has been classified tentatively into two categories: rare endemics and polymorphic inversions. By rare endemics we mean those inversions which have been found in a single locality only, almost always with a low frequency. Polymorphic inversions are those found in at least two different localities. This classification is necessary as the number of inversions described in a given species is a function of the amount of effort invested in collecting and sampling. For instance, in D. melanogaster over 320 different inversions have been found in nature, although only seven are at all widespread or common (Ashburner, 1989). Any comparison among species, therefore, must take into account the different efforts devoted to different species. The number of polymorphic inversions per species varies between zero in $D$. stalkeri and 14 in $D$. starmeri with an average of 3.9. The number of rare endemics per species varies between zero in $D$. stalkeri, $D$. venezolana and $D$. uniseta, and eight in D. buzzatii (the species most extensively sampled in the complex) with an average of 2 . These figures are relatively high for the repleta group with a mean value of only 2.1 polymorphic inversions per species (Wasserman, $1992 \mathrm{~b})$. Why the buzzatii complex is more polymorphic than the other complexes or subgroups, and why some species are more variable than others remain open questions.

\section{Acknowledgements}

A.R. started working on the cytology of D. stalkeri and D. richardsoni during his stay in the laboratory of $\mathrm{Dr}$ W. B. Heed (University of Arizona, Tucson) who kindly provided the stocks of these two species. Work supported by a postdoctoral Fulbright/MEC fellowship from the Ministerio de Educación y Ciencia (Spain) to A.R., grant No. BSR-8508457 from NSF and grant No. 669172 from CUNY-PSC to M.W.

\section{References}

ASHburner, m. 1989. Drosophila. A Laboratory Handbook. Cold Spring Harbor Laboratory Press, Cold Spring Harbor, New York.

BAIMAI, V., SENE, F. M. AND PEREIRA, M. A. Q. R. 1983. Heterochromatin and karyotypic differentiation of some neotropical cactus-breeding species of the Drosophila repleta species group. Genetica, 60, 81-92.

BARKER, J. S. F. 1982. Population genetics of Opuntia breeding Drosophila in Australia. In: Barker, J. S. F. and Starmer W. T. (eds) Ecological Genetics and Evolution. The Cactus-Yeast-Drosophila Model System, Academic Press, Sydney, pp. 209-224.
BARKER, J. S. F., SENE, F. M., EAST, P. D. AND PEREIRA, M. A. Q. R. 1985. Allozyme and chromosomal polymorphism of Drosophila buzzatii in Brazil and Argentina. Genetica, 67 , $161-170$.

BERENDES, H. D. 1963. The salivary gland chromosomes of Drosophila hydei Sturtevant. Chromosoma, 14, 195-206.

CLAYTON, F. E. AND GUEST, w. C. 1986. Overview of chromosomal evolution in the family Drosophilidae. In: Ashburner, M., Carson, H. L. and Thompson, J. N. Jr. (eds) The Genetics and Biology of Drosophila, Vol. 3e, Academic Press, London, pp. 1-38.

FONTDEVILA, A., RUIZ, A., ALONSO, G. AND OCAÑA, J. 1981. The evolutionary history of Drosophila buzzatii. I. Natural chromosomal polymorphism in colonized populations of the Old World. Evolution, 35, 148-157.

FONTDEVILA, A., PLA, C., HASSON, E., WASSERMAN, M., SANCHEZ, A., NAVEIRA, H. AND RUIZ, A. 1988. Drosophila koepferae: a new member of the Drosophila serido (Diptera: Drosophilidae) superspecies taxon. Ann. Entomol. Soc. Am., 81, 380-385.

HEED, W. B. AND RUSSELL, J. S. 1971. Phylogeny and population structure in island and continental species of the cardini group of Drosophila studied by inversion analysis. Univ. Texas Publ., 7103, 91-130.

MARIN, I., RUIZ, A., PLA, C. AND FONTDEVILA, A. Reproductive relationships among ten species of the Drosophila repleta group from South America and the West Indies. Evolution. in press.

PATterson, J. T. AND ALEXANDER, M. L. 1952. Drosophila wheeleri, a new member of the mulleri subgroup. Univ. Texas Publ., 5203, 129-136.

RUIZ, A. AND FONTDEVILA, A. 1981. Ecología y evolución del subgrupo mulleri de Drosophila en Venezuela y Colombia. Acta Científica Venezolana, 32, 338-345.

RUiz, A., FONTDEVILA, A. AND WASSERMAN, M. 1982. The evolutionary history of Drosophila buzzatii. III. Cytogenetic relationships between two sibling species of the buzzatii cluster. Genetics, 101, 503-518.

RU1Z, A., HEED, W. B. AND WASSERMAN, M. 1990. Evolution of the mojavensis cluster of cactophilic Drosophila with descriptions of two new species. J. Heredity, 81, 30-42.

RUIZ, A., NAVEIRA, H. AND FONTDEVILA, A. 1984. La historia evolutiva de Drosophila buzzatii. IV. Aspectos citogenéticos de su polimorfismo cromosómico. Genética Ibérica, 36, 13-35.

SENE, F. M., PEReIRA, M. A. Q. R. AND VILELA, C. R. 1982. Evolutionary aspects of cactus breeding Drosophila in South America. In: Barker, J. S. F. and Starmer, W. T. (eds) Ecological Genetics and Evolution. The CactusYeast-Drosophila Model System, Academic Press, Sydney, pp. 97-106.

SENE, F. M., PEREIRA, M. A. Q. R. AND VILELA, C. R. 1988. Contrasting patterns of differentiation inferred from traditional genetic markers in the process of speciation. Pacific Science, 42, 81-88.

STURTEVANT, A. H. AND DOBZHANSKY, TH. 1936. Inversions in the third chromosome of wild races of Drosophila pseudoobscura, and their use in the study of the history of the species. Proc. Natl. Acad. Sci. U.S.A., 22, 448-450. 
TOSI, D. AND SENE, F. M. 1989. Further studies on chromosomal variability in the complex taxon Drosophila serido (Diptera, Drosophilidae). Rev. Brasil. Genet., 12, 729-745.

WASSERMAN, M. 1954. Cytological studies of the repleta group. Univ. Texas Publ., 5422, 130-152.

WASSERMAN, M. 1960. Cytological and phylogenetic relationships in the repleta group of the genus Drosophila. Proc. Natl. Acad. Sci. U.S.A., 46, 842-859.

WASSERMAN, M. 1962. Cytological studies of the repleta group of the genus Drosophila. V. The mulleri subgroup. Univ. Texas Publ., 6205, 85-118.

WASSERMAN, M. 1963. Cytology and phylogeny of Drosophila. Am. Naturalist, 47, 333-352.

WASSERMAN, M. AND KOEPFER, H. R. 1979. Cytogenetics of South American Drosophila mulleri complex: the martensis cluster. More sharing of inversions. Genetics, 93, 935-946.

WASSERMAN, M. 1982. Evolution of the repleta group. In: Ashburner, M., Carson, H. L. and Thompson, J. N. (eds) The Genetics and Biology of Drosophila, Vol. $3 \mathrm{~b}$. Academic Press, London, pp. 61-139.

WASSERMAN, M., FONTDEVILA, A. AND RUIZ, A. 1983. Potential gene exchange between South American Drosophila species, with a description of a new species in the $D$. repleta group. Ann. Entomol. Soc. Am., 76, 675-677.

WASSERMAN, M. AND RICHARDSON, R. H. 1987. Evolution of Brazilian Drosophila mulleri complex species. J. Heredity, 78, 282-286.

WASSERMAN, M. AND WASSERMAN, F. 1992. Inversion polymorphism in island species of Drosophila. In: Hecht, M. K., MacIntyre, R. and Wallace, B. (eds). Evolutionary Biology. Vol 26. Plenum Press, New York, pp 357-381.

WASSERMAN, M. 1992. Cytological evolution of the Drosophila repleta species group. In: Powell, J. R. and Krimbas, C. B. (eds) Inversion Polymorphism in Drosophila, CRC Press, Inc., Boca Raton, Florida, pp. 455-541.

WharTon, L. P. 1942. Analysis of the repleta group of Drosophila. Univ. Texas Publ., 4228, 23-52.

white. M. J. D. 1948. Animal Cytology and Evolution. Cambridge University Press, Cambridge.

\section{Appendix A: salivary gland chromosomes of the interspecific hybrids}

The chromosomes of the $F_{1}$ hybrids produced in 16 different crosses, which amount to 14 interspecific combinations, were observed. The crosses are listed below with the species which provided the female parent first.

1 D. stalkeri $(1451.0) \times D$. buzzatii (BU-2ST). A single female larva dissected. Good general pairing except proximal $1 / 7$ of chromosome $\mathrm{X}$ and proximal end of chromosomes 3 and 5. Chromosomes X, 3 and 4 are homosequential. Chromosome 2 shows regions A-C5, D5-F1 and F5-H paired, regions C7-G4 of the D. buzzatii chromosome and F6-D2 of the D. stalkeri chromosome unpaired for they have no counterpart in the same place of the homologous chromosome, giving rise sometimes to two small single-chromosome loops (as expected for two overlapping inversions, $21 / \mathrm{z}^{7}$ ). Chromosome 5 has a single loop in proximal one-half $(5 \mathrm{~g} /+)$.

2 D. stalkeri $(1451.0) \times D$. borborema (1281.0). Twenty-eight larvae dissected. Chromosome X short and thick in males, unpaired in proximal $1 / 4$ in females. Chromosomes X, 3, 4 and 5 are homosequential except for minor band differences in proximal end of chromosomes $\mathrm{X}, 3$ and 5. Chromosome 2 shows regions $\mathrm{A}-\mathrm{B} 4$ and $\mathrm{F} 5-\mathrm{H}$ paired, rest of chromosome unpaired often giving rise to a complex multi-inversion loop (compatible with $2 \mathrm{l} / \mathrm{z}^{7} \mathrm{e}^{8} \mathrm{f}^{8}$ ).

3 D. stalkeri (ORV 28) $\times$ D. borborema (1281.0). Eight larvae dissected. Chromosomes as in cross 2 .

4 D. stalkeri (ORV 28) $\times$ D. venezolana $(\mathrm{VZ}-10)$. Two larvae dissected. Chromosome $\mathrm{X}$ has a small single loop in proximal one-half $(\mathrm{Xj} /+)$. Chromosome 2 shows one distal single loop $\left(2 \mathrm{e}^{7} /+\right)$ and a complex multi-inversion loop in proximal one-half (compatible with $2 \mathrm{l} / \mathrm{z}^{7} \mathrm{e}^{2}$ ). Chromosome 3 has one distal single loop $\left(3 \mathrm{r}^{2} /+\right)$ and a double loop in proximal one-half (3wv) $+)$. Chromosome 4 is homosequential. Chromosome 5 has a small single loop in proximal one-half $\left(5 \mathrm{~d}^{2} /+\right)$.

5 D. richardsoni (ORV 8b) $\times$ D. buzzatii (BU-C5). Two male larvae dissected. Chromosome 2 shows regions A-C5 and G3-H often paired, rest of chromosome unpaired implying a complex multi-inversion loop (compatible with $2 w^{7} y^{7} p^{8} / z^{7}$ ). Chromosomes 3 and 4 are homosequential. Chromosome 5 has a single loop in proximal one-half $(5 \mathrm{~g} /+)$.

6 D. richardsoni (ORV 6) $\times$ D. koepferae $(\mathrm{KO}-4)$. Two male larvae dissected. Chromosome 2 shows regions $\mathrm{A}-\mathrm{B} 2$ and $\mathrm{F} 3-\mathrm{H}$ paired, rest of chromosome unpaired implying a complex multi-inversion loop (compatible with $\left.2 w^{7} y^{7} / j^{9} k^{9}\right)$. Chromosome 3 has single loop in proximal one-half $\left(3 \mathrm{k}^{2} /+\right)$. Chromosome 4 has a small single loop in its proximal quarter $(4 \mathrm{~m} /$ + ). Chromosome 5 has a small single loop in proximal one-half $(5 \mathrm{w} /+)$.

7 D. richardsoni (ORV 6) $\times$ D. venezolana $(\mathrm{VZ}-10)$. Eighteen larvae dissected. Chromosome $\mathrm{X}$ shows a small single loop in proximal one-half $(\mathrm{Xj} /+)$. Chromosome 2 shows a distal single loop $\left(2 \mathrm{e}^{7} /+\right)$ and a complex multi-inversion loop involving proximal $2 / 3$ (compatible with $\left.2 w^{7} y^{7} / z^{7} e^{2}\right)$. Chromosome 3 has a distal single loop $\left(3 r^{2} /+\right)$ and a double loop in proximal one-half $(3 w v /+)$. Chromosome 4 is homosequential. Chromosome 5 has a small single loop in proximal one-half $\left(5 \mathrm{~d}^{2} /+\right)$.

8 D. richardsoni (ORV 8b) $\times$ D. venezolana $(\mathrm{VZ}-2)$. Six larvae dissected. Chromosome 2 has a distal single 
loop $\left(2 \mathrm{e}^{7} /+\right)$ and a complex multi-inversion loop in proximal $2 / 3$ (compatible with $\left.2 w^{7} y^{7} p^{8} / z^{7} e^{2}\right)$. All other chromosomes as in cross 7 .

9 D. martensis $(\mathrm{MA}-4) \times$ D. richardsoni (ORV 6). Two larvae dissected. Chromosome $\mathrm{X}$ has a single loop in proximal one-half $(\mathrm{Xj} /+)$. Chromosome 2 shows a single loop in distal one-half $\left(2 \mathrm{f}^{2} /+\right)$ and a complex multi-inversion loop in proximal one-half (compatible with $\left.2 w^{7} y^{7} / z^{7}\right)$. Chromosome 3 shows a distal single loop $\left(3 r^{2} /+\right)$ and a double loop in proximal one-half $(3 \mathrm{wv} /+)$. Chromosome 4 is homosequential. Chromosome 5 has a small single loop in proximal one-half $\left(5 \mathrm{~d}^{2} /+\right)$.

10 D. serido $(1431.4) \times D$. koepferae $(\mathrm{KO}-9)$. Eight larvae dissected. Excellent general pairing except in proximal end and distal tip of all chromosomes. Chromosomes X, 3, 4 and 5 homosequential. Chromosome 2 shows regions $\mathrm{A}-\mathrm{B} 1$ and $\mathrm{G} 1-\mathrm{H}$ paired, rest of chromosome would seem at first sight to have a double loop (corresponding to only two overlapping inversions); however, when the banding pattern is compared in detail, it is realized that two chromosome segments (D4 and F5), although paired, are not truly homologous implying four inversions of difference between the two chromosomes (as expected $\left.2 \mathrm{x}^{7} \mathrm{a}^{8} / \mathrm{j}^{9} \mathrm{k}^{9}\right)$.

11 D. koepferae $(\mathrm{KO}-9) \times$ D. serido (1431.4). Twelve larvae dissected. Chromosomes as in cross $\mathbf{1 0 .}$

12 D. borborema $(1281.0) \times D$. venezolana $(\mathrm{VZ}-10)$. Thirteen larvae dissected. Distal one-half of chromosome $\mathrm{X}$ always paired, proximal one-half often unpaired showing sometimes what seems to be a single loop $(\mathrm{Xj} /+)$. Chromosome 2 is usually totally unpaired implying a complex multi-inversion loop (compatible with $2 \mathrm{e}^{2} \mathrm{e}^{7}\left(\mathrm{e}^{8} \mathrm{f}^{8}\right)$. Chromosome 3 has a distal single loop $\left(3 r^{2} /+\right)$ and a double loop in proximal one-half $(3 \mathrm{wv})$ + ). Chromosome 4 is homosequential. Chromosome 5 has a small single loop in proximal one-half $\left(5 \mathrm{~d}^{2} /+\right)$.

13 D. koepferae $(\mathrm{KO}-9) \times D$. starmeri $(\mathrm{SM}-3)$. Twenty-four larvae dissected. Chromosome $\mathrm{X}$ has a single loop in proximal one-half $(\mathrm{Xj} /+)$. Chromosome 2 shows a complex multi-inversion loop (which corresponds to $2 j^{9} k^{9} / \mathrm{e}^{2} \mathrm{e}^{7}$ in some larvae and to $2 \mathrm{j}^{9} \mathrm{k}^{9} / \mathrm{f}^{2} \mathrm{x}^{6} \mathrm{z}^{6}$ in others). Chromosome 3 has one distal single loop $\left(3 \mathrm{r}^{2} /+\right)$ and a double loop in proximal one-half $(3 \mathrm{wv} /$
+ ). Chromosome 4 is homosequential. Chromosome 5 has a small single loop in proximal one-half $\left(5 \mathrm{~d}^{2} /+\right)$.

14 D. mulleri $(\mathrm{MU}-6) \times D$. buzzatii $(\mathrm{BU}-2 \mathrm{ST})$. A single female larvae dissected. Total asynapsis in all chromosomes. Homologous chromosomes are completely separated in most nuclei and only touch each other, when they do, in two or three points along the chromosomes' length. Inversion loops are not formed and synapsis is absent even in those chromosomes which are expected to be homosequential (e.g. chromosome 4). Hybrids are not useful for assessing the inversion differences between the parental species. 15 D. mulleri (MU-6) $\times$ D. martensis (MA-4). Two male larvae dissected. Chromosome $\mathrm{X}$ short and very thick. Total asynapsis in all autosomes. See comments to cross 14.

16 D. mulleri $(\mathrm{MU}-6) \times D$. venezolana $(\mathrm{VZ}-10)$. Five larvae dissected. Chromosome $X$ short and very thick in males. Total asynapsis in all chromosomes. See comments to cross $\mathbf{1 4}$.

\section{Appendix B: key to the chromosome segments of Figs 2 and 4}

A key to the segments of the salivary gland chromosomes shown in Figs 2 and 4 is provided. Each pair of letters in the two figures represents an unbroken segment of the $D$. repleta chromosome maps (Wharton, 1942).

Chromosome 2(Fig. 2)

\begin{tabular}{|c|c|c|c|c|c|}
\hline $\mathrm{AB}:$ & $\mathrm{A} \rightarrow \mathrm{A} 3 \mathrm{a}$ & QR: & $\mathrm{C} 7 \mathrm{e} \rightarrow \mathrm{D} 1 \mathrm{~g}$ & gh: & $\mathrm{F} 2 \mathrm{a} \rightarrow \mathrm{F} 3 \mathrm{a}$ \\
\hline CD: & $\mathrm{A} 3 \mathrm{a} \rightarrow \mathrm{B} 2 \mathrm{a}$ & ST: & $\mathrm{D} 1 \mathrm{~g} \rightarrow \mathrm{D} 3 \mathrm{~d}$ & ij: & $\mathrm{F} 3 \mathrm{a} \rightarrow \mathrm{F} 4 \mathrm{a}$ \\
\hline EF: & $\mathrm{B} 2 \mathrm{a} \rightarrow \mathrm{B} 3 \mathrm{a}$ & UV: & D $3 d \rightarrow D 4 a$ & $\mathrm{kl}$ : & $\mathrm{F} 4 \mathrm{a} \rightarrow \mathrm{F} 4 \mathrm{~d}$ \\
\hline $\mathrm{GH}:$ & $\mathrm{B} 3 \mathrm{a} \rightarrow \mathrm{B} 4 \mathrm{e}$ & WX: & $\mathrm{D} 4 \mathrm{a} \rightarrow \mathrm{D} 5 \mathrm{a}$ & $\mathrm{mn}:$ & $\mathrm{F} 4 \mathrm{~d} \rightarrow \mathrm{F}$ \\
\hline & $\mathrm{B} 4 \mathrm{e} \rightarrow \mathrm{C} 1 \mathrm{a}$ & YZ: & $\mathrm{D} 5 \mathrm{a} \rightarrow \mathrm{D} 5 \mathrm{c}$ & op: & $\mathrm{F} 6 \mathrm{a} \rightarrow \mathrm{C}$ \\
\hline L: & $\mathrm{C} 1 \mathrm{a} \rightarrow \mathrm{C} 3 \mathrm{f}$ & $a b:$ & $\mathrm{D} 5 \mathrm{c} \rightarrow \mathrm{E} 2 \mathrm{c}$ & qr: & $\mathrm{Gla} \rightarrow$ \\
\hline & $\mathrm{C} 3 \mathrm{f} \rightarrow \mathrm{C} 6 \mathrm{a}$ & $\mathrm{cd}$ : & $\mathrm{E} 2 \mathrm{c} \rightarrow \mathrm{F} / \mathrm{c}$ & st: & $\mathrm{G} 1 \mathrm{~g} \rightarrow \mathrm{H}$ \\
\hline
\end{tabular}

OP: $\mathrm{C} 6 \mathrm{a} \rightarrow \mathrm{C} 7 \mathrm{e} \quad$ ef: $\mathrm{F} 1 \mathrm{c} \rightarrow \mathrm{F} 2 \mathrm{a}$

Chromosome 3(Fig. 4)
AB: $\quad A \rightarrow B 1 c$
IJ: $\quad \mathrm{D} 4 \mathrm{~b} \rightarrow \mathrm{D} 5 \mathrm{a}$
$\mathrm{CD}: \quad \mathrm{B} 1 \mathrm{c} \rightarrow \mathrm{C} 5 \mathrm{~d}$
KL: D5a $\rightarrow$ E1a
EF: $\quad C 5 d \rightarrow D 3 d$
$\mathrm{MN}: \mathrm{E} 1 \mathrm{a} \rightarrow \mathrm{E} 4 \mathrm{a}$
OP: $\quad \mathrm{E} 4 \mathrm{a} \rightarrow \mathrm{F} 4 \mathrm{c}$
QR: $\mathrm{F} 4 \mathrm{c} \rightarrow \mathrm{G} 1 \mathrm{~h}$
ST: $\mathrm{Glh} \rightarrow \mathrm{H}$ 